\title{
DIE SOGENAAMDE MONDIGE MENS EN DIE JEUG VAN VANDAG
}

Vergun my vooraf 'n paar persoonlike woorde:

Die P.U. vir C.H.O. het my met hierdie uitnodiging 'n onverdiende eer aangedoen waarvoor ek ten seerste erkentlik is en dankbaar.

Tog was dit alleen met huiwering dat ek dit aanvaar het. En dit nie net omdat ek hier sou moes staan voor geëerde leermeesters aan wie se voete ek my nog altyd die tuiste voel nie, terwyl ek aan die ander kant dalk al 'n bietjie kontak met die studente van vandag sou kon verloor het - ek was tien jaar laas een van $u$; tien jaar is terselfdertyd volgens ons goeie ou Boeregewoonte die leeftydsverskil wat die een Afrikaner die ander as „,om" laat aanspreek (tensy die „oom" natuurlik 'n tante is). Die huiwering was veral omdat ek myself so goed ken en my onderwerp so sleg.

Dis 'n pragtige onderwerp. Van die mooiste daarvan is dat dit iets het van 'n blanko tjek - 'n mens kan haas enige kant daarmee uitgaan. En dit is miskien juis wat met 'n onderwerp behoort te gebeur om die gees van Inter-fakultêre lesings te adem. Dit sou my persoonlik egter taamlik wyd en ver weg voer van die vakgebied waar ek wetenskaplik die minste onseker voel, en ' $n$ mens voor die gevaar bring om verstrik te raak in wetenskaplike oppervlakkighede en niksseggende algemeenhede.

In dankbare erkentlikheid vir wat ek van die P.U. vir C.H.O. kon ontvang toe ek self nog hier student was, het ek tog die uitnodiging aanvaar. In hierdie gees is dit dan dat ek graag vanoggend tot $u$ sou wou spreek.

\section{Waar kom die mondige mens van ons tyd vandaan?}

Mondig is nie net iets wat ' $n$ mens is nie - dit is in die eerste plek jets wat 'n mens word. Hoe het die moderne mens 'n mondige mens geword?

Eintlik het die mens al 'n paar keer deur die loop van die eeue mondig geword. Die Renaissance was so 'n ontwaking van die selfstandig-kritiese gees; die Verligting (die Aufklärung) het ook 'n impuls in die rigting meegebring; 'n wêreldbeweging in die volle sin van die woord het dit egter eers in die twintigste eeu geword. 
Hierdie mondigwordingsproses is in die negentiende eeu al daadwerklik aan die gang. Miskien is een van die belangrikste redes waarom die moderne mondigheidskultus eers so redelik laat na Suid-Afrika begin oorwaai het, geleë in die feit dat ons negentiende eeu so anders as dié van Europa verloop het.

By ons was dit 'n haas ongelooflike periode van stryd en verandering, wat alle aandag opgeëis het vir die onverbiddelike worsteling om voortbestaan en die oog slegs terloops op die buitewêreld laat val het. 'n Hele binneland moes ontgin word; staatstrukture het gekom en gegaan. Die oorloë wat Europa van die twintigste eeu tot in sy fondamente geskud het, het SuidAfrika reeds in die negentiende eeu ten deel geval.

Vir Europa was die negentiende eeu ook 'n tyd van stryd en verandering - dit begin met die Franse Rewolusie en die Napoleontiese oorloë, en dit eindig met 'n hele reeks selfstandige volkere; die industriële rewolusie gaan met rasse skrede voort; Marx en die Kommunisme verskyn op die toneel. En tog het die negentiende eeu in Europa 'n totaal ander gees geadem as in Suid-Afrika. By ons was dit die stryd om lewe en dood - dár was dit 'n algemene gees van vooruitgang, groei, optimisme en grenslose selfoorskatting. En al was die posisie van die arbeider in die landbou en veral in die industrie hemeltergend, die toonaangewende groep het daarvoor geen oog gehad nie - dit was alleen vir die asemrowende vordering van die wetenskap (veral die natuurwetenskappe), die ontdekking na ontdekking wat die mens dag by dag 'n groter heerser gemaak het, die vlugte van die menslike verstand wat altyd hoër klim en van geen einde skyn te weet nie, die innerlike adel van die mens wat so duidelik na buite straal. Nog net 'n kwessie van tyd, dan is die paradys daar, gebou deur mensehande. Die mens sal die hemel op aarde laat daal.

In die godsdiens van die tyd was daar dan ook vir God nouliks 'n plek - die mens het voluit in die middelpunt gestaan. En sonde, ag ja, dis eintlik meer 'n kwessie van onkunde wat buitendien binnekort deur algemene onderwys en volksopvoeding heeltemal uit die weg geruim sal word ... deur die mens, die soewereine, mondige mens wat aan God eintlik nie werklik behoefte het nie. Die drie-eenheid van die Liberale Teologie is dan ook die vaderskap van die Opperwese, die broederskap van alle mense, en die oneindige waarde van die mensesiel.

Die negentiende eeu het eintlik selfs na die eeuwisseling 
self nog ongesteurd in Europa voortgeduur. Engeland se onreg aan die verre suidpunt van Afrika was iets van 'n skok, maar dit het ook gou genoeg weer verby gegaan.

En toe het 1914 uit die wolkelose hemel ineens die Twintigste Eeu die geskiedenis laat instorm met die uitbreek van die Eerste Wêreldoorlog. In plaas van die hemel bars die hel los. Die mees verligte volke roei mekaar uit met behulp van dieselfde wetenskap wat die paradys moes grondves. Europa het nouliks herstel van die skok, of Hitler en al die gruwels van die Nazi-terreur is daar om die Tweede Wêreldoorlog in te lei. Die Eerste Wêreldoorlog was geen groeipyn van die nuwe supermens nie, slegs voorspel tot veel erger; 'n gruwelgolf spoel opnuut oor die mees begaafde, mees verligte, mees teologiese volkere en laat dood en verskrikking agter. Nou is dit op sy beurt weer Suid-Afrika wat hierdie oorloë slegs op 'n afstand meemaak, en daarom nouliks selfs by benadering ' $n$ indruk kan vorm van die radikale ontwrigting wat dit beteken het, nie in die minste nie vir die Europese jeug. En voor die oorlogswolke heeltemal opgeklaar het, is die paddastoel-wolke van die atoombom daar, en Rusland, vir die eerste keer wêreldmoondheid van onmiskenbare formaat, Rooi Sjina met sy miljoene massa, Afrika en Asië wat ontwaak uit die slaap van eeue, spanning op spanning: Korea, Hongarye, Kuba, Viëtnam... tot hoelank?

Ook in hierdie ontwikkeling is die godsdiens ten nouste betrokke. Die goedkoop optimisme en vooruitgangsgeloof van die negentiende eeu maak plek vir 'n diepe moedeloosheid, 'n roue radeloosheid. Aan sonde het die mens nou geen twyfel nie - ook atheiste praat van die duiwelse, die demoniese in en om die mens. Maar eintlik is daar nou ewe min as in die negentiende eeu vir God plek - nou egter nie omdat die mens Hom nie nodig het nie, maar omdat die mens by voorbaat al weet dat God tog ook nie kan help nie. Die eksistensialistiese lewensgevoel polsslag van angs, wanhoop, totale uitsigloosheid.

Dit alles kon by die jeug nie verbygaan nie. Die oorlogsjeug van die Tweede Wêreldoorlog het ' $n$ jeug sonder ' $n$ jeug geword, kinders sonder 'n kindertyd, mense wat dit eenvoudig moes oorslaan en lank voor hulle tyd oud en volwasse moes word - of te gronde gaan.

Hierdie abnormale ontwikkeling moes hulle in 'n totaal onderstebo wêreld deurmaak. Waar die vyand die besetter was, 
was alles wat vroeër verkeerd was, nou reg. Wie steel, steel van die vyand, en is dus ' $n$ held. Wie lieg, lieg vir die vyand, en is gevolglik 'n patriot. Die normbesef word radikaal omgekeer; die lewensonsekerheid bring 'n algehele devaluasie van waardes mee; 'n gesagskrisis is onvermydelik; die jeug voel in die steek gelaat deur die ouer generasie wat wel baie kon praat, maar niks kon doen om die krisis af te weer nie; en wie kan nog werklik vir iets warm word as al die ideale van 'n leeftyd ineens in duie gestort het? Wie spaar as 'n oorlog skielik weer alles kan verwoes? Wie bou aan 'n toekoms as die verlede uitgeloop het op een kolossale puinhoop?

En so het die oorlogsjeug dan te voorskyn getree: gedesillusioneerd, passief, nihilisties, opstandig, sonder eerbied vir enigiemand of enigiets. Wie niks het nie, het ook niks te verloor nie.

Die tyd sal moet leer of ons op die hakke van die Tweede Wêreldoorlog 'n nuwe periode binnegegaan het; ' $n$ mens sou dit wel in verskillende opsigte wou vermoed. Op die oorlogsjeug het 'n nuwe generasie jongmense gevolg wat die oorlog nie self meegemaak het nie; die jeug van ander wêrelddele het saam met hierdie groep 'n afsonderlike tienerkultus begin vorm. Die Teologie het langer tyd vir selfkorreksie na die Tweede Wêreldoorlog gekry as wat dit gehad het na die Eerste - en dit ook gebruik. Waar die negentiende eeu die tyd was van die Immanentisme (toe God vermenslik is en die mens vergoddelik), het die reaksie tussen die twee wêreldoorloë die Transendentisme gebring: die „god" wat eens so naby was, het welhaas onbereikbaar ver geword. Die volgende stap was om hierdie „god" dood te verklaar - en omdat hy al reeds so ver weg. geskuif was, is die skok van die operasie nouliks gevoel. Die sekularisering van die Teologie het sy konsekwensie bereik.

Sekularisasie beteken letterlik „verwêreldliking”. Dit is oorspronklik gebruik vir die onteiening van besettings van die kerk deur die staat. Dit kry spoedig ook 'n figuurlike betekenis as 'n protes teen die verkerkliking van die lewe soos bv. die RoomsKatolisisme. Sekularisme gaan nog 'n stap verder: die lewe moet nie net van die kerk as instituut ontvoog word nie, maar ook van God en van alles wat bo-wêrelds sou wees. Die mondige mens vereis immers totale emansipasie. Daarom mós die mondige mens van ons tyd 'n „God is dood"-teologie kry. Hy het. 


\section{Waarin tree sg. mondigheid van die moderne mens veral na vore?}

En nou gaan ek my nie waag aan 'n gedetailleerde ontleding van wat die mondigheid van die moderne mens alles behels nie - dik boeke is daaroor geskrywe, en dis nog nie naastenby die einde nie. Ek wil alleen maar mef $u$ vra wat die prominentste is in die mondigheid van die moderne mens - wat daarin op die voorpunt staan, die toon aangee, waarin hierdie mondigheid veral tot uitdrukking kom.

Waar die twintigste eeu twee groot wêreldoorloë opgelewer het, het die negentiende gesorg vir twee groot rewolusies: 'n industriële en 'n politieke.

Hierdie twee terreine het hulle voorsprong in die mondigwordingsproses van die moderne mens behou. Die twintigste eeu het, behalwe twee wêreldoorloë, darem ook twee groot ontploffings opgelewer waarin die industriële rewolusie en die politieke omwenteling van die negentiende eeu bly naklink het.

Die skouspelagtige ontwikkeling van wetenskap en tegniek het die twintigste eeu onmiskenbaar gestempel, en nie soseer die kultuur of die filosofie, die kuns of die teologie nie. Die mens is besig om sowel die mikro- as die makro-wêreld te verower: die atoom ontsluit sy geheime, terwyl mensewerk steeds dieper die hemelruim indring. Om hier van 'n ontploffing te praat, is nie vergesog nie: $90 \%$ van die natuurwetenskaplikes van alle tye leef vandag.

Die tweede ontploffing is op politieke gebied - die rewolusie van dekolonialisering, van die ontvoogding van die AfroAsiatiese lande.

Met hierdie twee pylers - 'n natuurwetenskaplik-tegniese en 'n politieke - is die mondigheid van die moderne mens oog. lopend eensydig.

Soos die Afro-Asiatiese lande steeds meer tot die besef gedwing word dat politieke onafhanklikheid sonder ekonomiese selfstandigheid 'n mankbeen-mondigheid is, so blyk al hoe duideliker dat 'n mens wat natuurwetenskaplik-tegnies 'n reus mag word maar geestelik-kultureel 'n dwergie bly, 'n gevaar vir homself is. Hy kan al hoe meer die natuur beheers, homself egter al hoe minder. Hy is besig om die hemelruim te verower, maar 'n blywende vrede op die ou klein aard-planeetjie bly steeds buite sy bereik. Sy kommunikasie-middels maak 
die wêreld al hoe kleiner, maar die eensaamheid word al hoe groter. Hy skep outomate om hom te dien, net om op sy beurt deur hulle beheers te word. Hy kan organiseer soos nooit te vore nie, maar hy word telkens 'n slagoffer van sy eie organisasie. Hy is van harte 'n aktivis, maar kla terselfdertyd dat hy geen rus kry nie. Hy glo net in wat hy sien, maar hunker steeds na 'n voller lewe.

As die mondigheid van die moderne volwassene so eensydig is, kan van die jeug nouliks 'n gebalanseerde ontvoogdingsproses verwag word.

'n Eie jeugstyl is ontwikkel, tot kleredrag en musiek toe maar dit was enkelinge wat geskep... en fortuine gemaak het.

Sy individualiteit probeer die jongmens in die massa behou deur teen alles en almal te wees - net om daarin weer saam met die massa in opstand ter wille van die opstand verstrengel te raak.

Wie van kleins af self kon kies en toe onvermydelik telkens sy kop gestamp het, kies later vir alles, vir niks; sy relativisme voer hom na nihilisme. Hy is beterweterig, maar hy oortuig niemand, homself allermins.

Hy is mondig, maar diep in sy hart huil hy om werklik kind te kan wees. Die gelykenis van die verlore seun het die tragedie van die verlore vader geword.

\section{Waar het sy mondigheid ontspoor?}

En weer gaan ek my uitdruklik tot hierdie enkele vraag beperk, hoe boeiende studie dit ook al is (en noodsaaklik!) om presies vas te stel wat mondigheid volgens die Skrif is. Dit sou ons uiteraard veels te wyd voer. Daarom slegs die vraag: waar het die mondigheid van die moderne mens die spoor byster geraak?

Reeds al by die wortel. Die oomblik toe die mens sy mondigheid gesien het as om sy eie baas te wees, het hy sy mondigheid laat ontspoor. Die mens kan nie sy eie baas wees nie: hy is altyd kind of slaaf - kind van God of slaaf van die duiwel.

Hy bely dit as hy God aanspreek as „Here" - Meester, Eienaar, Besitter.

Die Koninkryk wat die Bybel verkondig is die Koninkryk van Gód - dit beteken in die eerste plek dat Gód regeer, en dui verder die terrein aan van Sý heerskappy en die vrugte van Sý bewind. 
My enigste troos is dat ek met liggaam en siel, in lewe en in sterwe, nie aan myself nie, maar aan my getroue Saligmaker Jesus Christus toebehoort.

Selfverloëning en nie selfhandhawing nie is ware selfverwesenliking voor God.

Die mondige mens van die moderne tyd het op dieselfde punt as die eerste mens van die paradys ontspoor: toe hy die beskikking oor sy lewe in sy eie hande wou neem.

In hierdie opsig ken die Bybel nie so iets as mondigheid nie. Die kind van God word groot, maar nooit te groot vir sy Vader nie.

Aan die ander kant weet die Bybel nie net van volwassenes wat kinders moet word nie, maar ook van kinders wat volwasse moet word.

Die Korinthiërs was uitnemend onder die indruk van hulle geweldige geestelike rypheid, volwassenheid, mondigheid; tog moet juis hulle dit hoor:

„En ek, broeders, kon met julle nie spreek soos met geestelike mense nie, maar soos met vleeslike, soos met klein kinders in Christus. Ek het julle met melk gevoed, nie met vaste spys nie, want julle was nog nie daartoe in staat nie, en julle is nou nog nie daartoe in staat nie... (1 Kor. $3: 1-2)$.

„Toe ek 'n kind was, het ek gepraat soos 'n kind, gedink soos 'n kind, geredeneer soos 'n kind; maar nou dat ek 'n man is, het ek die dinge van 'n kind afgelê" (1 Kor. $13: 11$ ).

„Broeders, moenie kinders wees in die verstand nie, maar wees kinders in die boosheid en wees volwassenes in die verstand" (1 Kor. $14: 20$ ).

Geestelike luiheid het die lesers van die Hebreërbrief geestelik onvolwasse gemaak: hulle het "traag geword om te hoor", hulle "het weer behoefte aan melk en nie aan vaste spys nie". „Want elkeen wat melk gebruik, is onervare in die woord van geregtigheid, omdat hy 'n kind is. Maar vaste spys is vir die volwassene, vir die wat geestesvermoëns besit deur die gewoonte geoefen, om goed van kwaad te onderskei" (Hebr. 5 : 11-14).

Hiervoor is dan ook die ampte in die kerk ingestel: „om die heiliges toe te rus vir hulle dienswerk, tot opbouing van die liggaam van Christus, totdat ons almal kom tot 
die eenheid van die geloof en van die kennis van die Seun van God, tot 'n volwasse man, tot die mate van die volle grootte van Christus; sodat ons nie meer kinders sou wees nie wat soos golwe geslinger en heen en weer gedryf word deur elke wind van lering, deur die bedrieëry van die mense, deur sluheid om listiglik tot dwaling te bring..." (Ef. $4: 1-14$ ).

Die mens wás onmondig - vóór Christus. Tot dan het God die mens nie net soos in 'n tronk in veilige bewaring gehou onder die wet nie (Gal. $3: 23$ ) - die wet was vir die mens ook iets wat nie so ver is van die kindermeid van ons tyd nie: die Griekse pedagoog of tugmeester. (Die pedagoog was 'n slaaf onder wie se toesig die Griekse seun tussen die jare van so ses en sestien gestel is). Met die koms van Christus is die "tug. meester na Christus" nie meer nodig nie (Gal. 3 : 23-25), staan die gelowige nie meer onder voogde en bestuurders nie (Gal. 4:2) - Christus het hom ryp en mondig gemaak, en dit mag hy hom nie laat ontroof nie:

„Staan dan vas in die vryheid waarmee Christus ons vrygemaak het, en laat julle nie weer onder die juk van diensbaarheid bring nie" (Gal. $5: 1$ ).

Die kerk van die Nuwe Testament is dan ook ' $n$ mondige gemeente, geen onvolwasse leke wat onder die bestuur van 'n hoër geestelikheid staan nie - bv. Rom. $15: 14$ :

„Maar ek self ook, my broeders, is oortuig aangaande julle, dat julle self ook vol van goedheid is, vervuld met alle kennis, in staat om ook mekaar te vermaan."

By hierdie steekproef uit die briewe van Paulus sou nog die verskillende uitsprake gevoeg kon word waar dit gaan oor 'n groei en ' $n$ toeneming, 'n stigting (dit is, opbouing) en 'n wasdom; dit is egter reeds duidelik genoeg dat die Bybel nie die sg. mondigheid van die moderne mens repudieer bloot vanweë die pretensie tot mondigheid as sodanig nie, maar op grond van dit vat as mondigheid aangedien word. Soos die Bybel geen vryheid ván God, los van God, ken nie maar alleen 'n vryheid tot God, in Hom, so is die Bybelse mondigheid geen emansipasie van God, 'n ontvoogding los van God nie, maar juis 'n selfstandigheid, 'n volwassenheid, in en deur Hom.

Hoe nader die mens aan God lewe des te mondiger is hy. Volkome liefde teenoor God en volkome liefde teenoor die naaste is die grootste mondigheid. 
Mondigheid is dat die huisheer sy diensknegte hulle opdragte kan gee, na 'n ver land kan reis, en weet dat hulle dit ook in sy afwesigheid uitvoer (Luk. 19 : 11 e.v., of Matth. $25: 14$ e.v.). Mondigheid is dat Christus nie net aan die regterhand van die Vader is nie, maar in die Syne gestalte kry (Gal. $4: 19$ ). Die Woord het vlees geword (Joh. $1: 1$ ) - maar word in hierdie sin telkens opnuut vlees in die lewe van die gelowiges wat immers Sy liggaam is.

Daarom is die belewing van Christelike mondigheid nie altyd dieselfde nie. Die beginsels bly onveranderd dieselfde; die uitlewing daarvan verskil van tyd tot tyd en van plek tot plek, van mens tot mens en van omstandigheid tot omstandigheid.

Die jeug van elke tyd het nie net die reg tot 'n eie belewing van die Christelike mondigheid nie, maar ook die plig daartoe.

Mondigheid is iets anders as om in vervoering te wees oor elke nuwe geestelike mode - om teen die oue te wees net omdat dit oud is, en vir die nuwe net omdat dit nuut is. Iemand wie se geestelike ontwikkeling vasgehak het by die mode van ' $n$ bepaalde tyd, is egter ewemin mondig, hy is eweseer 'n modeChristen of ' $n$ mode-Afrikaner, net... 'n verouderde modeChristen, 'n verouderde mode-Afrikaner.

Die mondigheid van die gelowige vereis juis dat hy telkens ontvoog word van die manier waarop 'n vorige generasie die onveranderlike evangelie vertolk het in die taal van hulle tyd, sodat die volgende geslag dit opnuut in die taal van hulle tyd kan oorsê.

Die mondige mens moet dus 'n mens van sy tyd wees wat sy tyd deur-en-deur ken. Ook die jeug van vandag hoef alles behalwe wêreldvreemd te wees, kan dit allermins bekostig om wêreldvreemd te wees. Want juis in en teenoor die wêreld sal hulle as mondige Christene moet staan. Hoe hulle dit presies sal doen, is hulle verantwoordelikheid, hoort by hulle mondigheid om ter syner tyd daaroor die beslissing te neem. Die ouer geslag kan raad en advies gee solank as die jeug nog besig is met voorbereiding vir die volle mondigheid; by die mondigheid van die ouer generasie hoort egter ook dat hulle sal weet wanneer om terug te tree, wanneer hulle eietydse belewing van die onveranderlike evangelie plek moet maak vir die nuwe belewing van ' $n$ nuwe tyd.

Juis in hierdie kombinasie van die oue en die nuwe, die 
verbinding van die blywende en die verganklike, lê die gebalanseerdheid van waaragtige mondigheid. Die Reformatore was konserwatief en daarom progressief: omdat hulle wou terugkeer na die egte skat van die oeroue evangelie, was hulle bereid om nuwe weë vir die kerk van hulle tyd aan te durf. As die Voortrekkers bloot tradisioneel-konserwatief was, sou die Groot Trek 'n onmoontlikheid gebly het; die ou vryheidsideaal het hier egter letterlik tot die gaan op nuwe weë geroep.

Die tragedie van die sg. mondigheid van die moderne mens is nie dat hy te relatiwisties is nie, maar juis dat hy homself te absoluut neem. Hy het God uit sy wêreldbeeld verwyder en toe self in die vakuum ingetree. Hy het homself tot maatstaf verhef, maar juis daarom in 'n gesags- en normkrisis ingestort. Alles het relatief geword, behalwe die dogma dat alles relatief is. Sy wêreldbeeld is geslote vir elke geloof, behalwe vir die geloof dat die wêreld 'n geslote wêreld is.

Agter sy aanspraak op mondigheid skuil 'n geweldige minderwaardigheidskompleks en verregaande hoogmoed. 'n Minderwaardigheidskompleks, want wie werklik mondig is, kan dit bekostig om beskeie te wees - hy hoef homself nie gedurig daarvan te oortuig dat hy groot is nie. Maar terselfdertyd ook 'n verregaande hoogmoed: waarom sou dit nou juis vir die mens van die twintigste eeu so ' $n$ onbegonne offer wees om die skandalon van die kruis te aanvaar? Waarin was dit makliker vir die Joodse tekenvraer of die Griekse wysheidsoeker van 1 Kor. 1? Sou almal voor hom 'n god na hulle beeld, na hulle gelykenis gemaak het, en hy die eerste wees om hieraan te ontkom... maar terselfdertyd, self niks, met 'n niks te sit waar God eens sou gewees het? Hy het God doodverklaar toe die wêreld vir hom 'n grafkelder geword het - wat is dit anders as om die tydsgees tot religie te verhef? Hy het God eers uit die wêreld weggedefinieer, en toe kon hy Hom ook nêrens meer vind nie. Daarom is die sg. moderne mondige mens ten diepste so onmondig, so onmodern. Talle prototipes het deur die eeue gekom... en weer gegaan.

Maar in alles het God gebly. En alleen wie klein voor Hom is, is groot voor die mense. Alleen wie kind in Hom is, is volwasse in die wêreld. Alleen wie onder Sy voogdy bly, is mondig, in die moderne en in alle tye.

Krugersdorp.

Tjaart van der Walt. 